\title{
ГЕНДЕРНАЯ ПРОБЛЕМАТИКА В НЕМЕЦКОЙ КЛАССИЧЕСКОЙ ФИЛОСОФИИ
}

\section{Т.И. Власова}

Глубинная трансформация общественного сознания, присущая нашему времени, во многом основана на трансформации мировоззренческих стереотипов, связанных со способами социализации пола, то есть гендерной проблематикой, составной, неотъемлемой, более того, фундаментальной частью которой являются гендерные стереотипы. Рассмотрение особенностей их интерпретации в концепциях выдающихся представителей немецкой классической философии даст возможность понять суть многих современных гендерных проблем.

В контексте заявленной в названии статьи проблематики значимыми являются разработки О. Гомилко, И. Грабовской, Н. Зборовской, С. Павлычко, К. Милет, И. Кона, Н. Чухим и др. Особенностью подходов, характерных для перечисленных исследователей, является рассмотрение гендерной проблематики в контексте современной культуры и культур прошлого, интерпретация гендерных стереотипов в общем контексте феминистской или гендерной проблематики. Рассматривая проблему дефинирования гендерных понятий, импонирующие автору исследователи подчеркивают существенную разницу между полом и гендером, акцентируя внимание на том, что пол связан с анатомией и физиологией, гендер же-это сфера мыслей, чувств, фантазий, которые имеют не биологическую, а культурную коннотацию и интерпретируются в качестве родовой сущности человека. В частности, ярким примером такого подхода являются разработки С. Павлычко.

Новизна предлагаемого в статье подхода заключается в выделении гендерной проблематики в концепциях представителей немецкой классической философии в качестве особого, исключительно значимо-

Актуальні проблеми духовності 
го в процессе культурного развития феномена, требующего выявления основных парадигмальных подходов к его интерпретации.

Современная отечественная исследовательница О. Гомилко утверждает: классической модерной метафизике настолько удалось десоматизировать человека, что вместе с этим актом была снята и специфика мужского и женского. Именно эта десоматизация и позволила рационалистической философии обосновать феномен еgо, превратив его в базовый метафизический принцип. «Концепт еgo, - подчеркивает исследовательница, - манифестирует крайне радикальную онтологическую позицию, защита которой без десоматизации человека вряд ли была бы успешной» $[1$, с. 47$]$.

Возможно ли принять вышеприведенное утверждение безоговорочно? Действительно ли «снятие» проблематики тела было настолько радикальным? Если это так, то возможно ли (и в каких контекстах) существование гендерной проблематики в модерной философии?

Анализ творчества И. Канта указывает на необходимость смягчить столь жесткий вывод отечественной исследовательницы. Метафизика пола, присутствующая в его философии, автоматически интерпретирует и проблему человеческой телесности. Правда, следует согласиться с мнением большинства исследователей творчества основателя немецкой классической философии, которые, отмечая значимость кантовских прозрений в осмыслении сущности философии, истины, познания, указывают, что в области решения проблемы пола мыслитель не оригинален (см., напр.: [2, с. 37]).

$\mathrm{K}$ проблематике пола основатель немецкой классической философии обращался в целом ряде своих работ. В частности, это трактат по эстетике «Наблюдения над чувствами возвышенного и прекрасного» и этический трактат «Метафизика морали». Данная проблематика присутствует и в его личной переписке. Размышляя над сущностью возвышенного и прекрасного, Кант интерпретирует эти категории не только как обслуживающие чистое эстетическое сознание, но и прослеживает их функционирование в реальной жизни, в частности в качестве характеристик носителей половых отличий. Исследователи правы, подчеркивая, что в работах, посвященных этической и эстетической проблематике, философ не отклоняется от парадигмы социальной дифференциации полов Руссо. Следует согласиться и с мнением критиков, что исходным принципом кантовского анализа является утверждение природного сущностного отличия женщин и мужчин. Сущность женщины в указанных трактатах определяется эссенциалистски и понимается как природное бытие [7, с. 59-60]. 
Обратившись к кантовской «Метафизике нравов», представляющей собой своеобразный панегирик правосознанию, несложно проследить, как в размышления о частной собственности привносится гендерная составляющая. Рассматривая частную собственность как результат исторического развития, Кант утверждает, что она является основой гражданского общества. В то же время постоянно подчеркивается, что сами отношения владения и деление на «мое» и «твое»не изначальны. Философ особо отмечает тот факт, что человек не может и не должен быть объектом собственности. Человеком как субъектом отношений, возникающим в процессе становления собственности, владеть нельзя. И только лишь в одной сфере, а именно в браке, подчеркивает Кант, который покоится на сфере вещно-личного права, люди рассматривают себя как вещи, отдавая себя друг другу во взаимное пользование. Философ дефинирует брак как «соединение двух лиц разного пола ради пожизненного обладания половыми свойствами другого» [5, с. 192], при этом подчеркивается равенство вступающих в брак сторон. Это равенство утверждается не только в качестве равного права на наслаждение. Кант пишет, что не только муж может потребовать ушедшую от него жену, но таким же правом может воспользоваться и жена. Исследователь немецкой классической философии А.В.Гулыга отмечал, что заимствуя два первых принципа - принципы свободы и равенства у французской революции, и заменив ее третий принцип братство - на «гражданскую самостоятельность», Кант подчеркивал важность их воплощения в сферу правовых отношений в государстве, указывая на особую необходимость наделения граждан избирательным правом. Именно это способствовало утверждению людей в качестве свободных и равных граждан государства. В то же время философ лишает избирательных прав детей, женщин и слуг, поскольку они, по мнению Канта, несамостоятельны. А.В. Гулыга подчеркивал совпадение кантовской позиции с представлениями его времени: «Что касается избирательных прав, то, кстати сказать, якобинская конституция 1793 г. не предоставляла их женщинам. Это было в духе времени» [3, с. 99]. Справедливость этого замечания лишь подчеркивает тот факт, что дав миру непреходящую по своей значимости метафизику, Кант не смог предложить ничего нового и оригинального в проблематике пола, развивая характерные для своего времени эссенциалистские представления, основывающиеся на традиционных гендерных стереотипах, хотя это и не умаляет значимость кантовской антропологии, основанной на внимательном и вдумчивом отношении к проявлениям различных человеческих состояний, чувств и качеств. Особый интерес 
вызывают размышления основателя немецкой классической философии о чувстве любви.

Рассматривая любовь как метаморфозу полового инстинкта, возникшую в результате окультуривания низменного животного вожделения, Кант отмечал значимость воображения и порожденных культурой запретов при реализации полового влечения. Именно определенного рода запреты и развитие воображения привели к эстетизации, возвышению и трансформации вожделения в чисто человеческие формы осуществления. «Человек вскоре замечает, - писал Кант, - что половое возбуждение, которое основывается у животньх на преходящем, большей частью периодическом влечении, способно у него принять характер более длительный и даже более интенсивный благодаря воображению, которое поддерживает эту эмоцию, умеряя ее, но делая ее в то же время тем продолжительнее и единообразнее, чем больше предмет чувства удален, и что в силу этого устраняется пресыщение, являющееся необходимым последствием полного удовлетворения чисто животной потребности... Отказ и был тем волшебным средством, превратившим чисто чувственное влечение в идеальное, животную потребность - в любовь, ощущение, просто приятное, - в понимание красоты сначала в человеке, а затем и в природе» [6, с. 47].

В аспекте анализа гендерных стереотипов в философии И. Канта следует обратить внимание на решение мыслителем проблемы «темных представлений». Канта с молодости интересовал вопрос о причинах возникновения и роли «темных представлений» в духовной жизни человека. Мыслитель писал: «На большой карте нашей души, так сказать, освещены только немногие пункты, - это обстоятельство может возбуждать у нас удивление перед нашим собственным существом; ведь если бы некая высшая сила сказала: да будет свет!, то без малейшего содействия с нашей стороны перед нашими глазами открылось бы как бы полмира [4, с.366]. Обратив внимание на значимость воображения в формировании многих темных представлений, Кант уже в конце жизни, в последней из опубликованных работ «Антропология с прагматической точки зрения» подчеркивал, что человеческий рассудок очень часто не способен справиться и противодействовать темным представлениям, даже понимая их нелепость, поскольку они покоятся не в сфере разума, а в сфере аффектов. К сфере таких явлений относится и половая любовь, во многом основанная на неосознаваемых человеком представлениях, покоящихся в нашей душе.

В одном из разделов «Антропологии с прагматической точки зрения», названном «Характер пола», Кант репрезентирует свою теорию 
пола, фактически воспроизводя традиционные для его эпохи гендерные стереотипы и не более. Как и философы прежних эпох, Кант не придает проблеме пола самостоятельного значения, формируя абстрактно-эссенциалистскую точку зрения. Раздел «Характер пола» отражает взгляд немецкого мыслителя на основы различия полов. С точки зрения Канта, половые различия обусловлены природным обоснованием ролевой специфики реализации мужчин и женщин в обществе. Утверждая, что пол имеет природное предназначение, мыслитель подчеркивал, что половая конституция женщины свидетельствует о ее предназначенности быть продолжательницей рода. Сложившаяся и устоявшаяся в культуре дифференциация функций, приписываемых представителям разных полов, целесообразна в силу ее природности. «Каждая сторона, - писал Кант, - должна в развитии культуры превосходить другую по-разному: мужчина женщину - своей физической силой и своим мужеством, а женщина мужчину - своим природным даром овладевать склонностью к ней мужчины» [4, с. 402].

Развивая свою мысль, Кант отмечает природное доминирование мужчины, подчеркивая, что особенности женщины представляют для философии значительный интерес именно в силу ее вторичности: «В еще нецивилизованном состоянии превосходство всегда на стороне мужчины. - Вот почему в антропологии характерные особенности женщины больше, чем особенности мужчины, суть предмет изучения для философа» [4, с.402]. Апофеозом этого размышления является утверждение о целесообразности восприятия природной специфики половых различий и необходимости именно на ней основывать общественную деятельность и жизнь. Кант убежден, что половые различия необходимы прежде всего для продолжения человеческого рода. Он отмечал, что под влиянием культуры природные задатки женщины могут претерпевать значительное изменение, но это изменение не определяется задачами развития женской личности или ее общественным ростом. Их трансформация идет в направлении достижения единственной цели - улавливания и удержания мужчины. Кант подчеркивал, что задатки женщин служат единственно тому, чтобы быть при мужчине-муже для осуществления природной предопределенности - воспроизводства и выращивания потомства.

Размышляя о женском характере, философ указывал на его особенности, которые наиболее ярко проявляются, когда женщине предоставляется относительная свобода в сексуальном отношении. Это так называемые периоды роскоши в развитии цивилизаций, когда женщине может быть позволена свобода самовыявления. Именно в такие 
периоды, утверждал Кант, проявляется присущее женщине притязание на завоевание всего мужского пола. Философ писал: «Своей благосклонностью к мужчинам женщина притязает на свободу и вместе с тем на завоевание всего мужского пола. - Хотя эта склонность под именем кокетства пользуется дурной славой, все же она не лишена действительного основания для своего оправдания, ибо молодой женщине всегда грозит опасность остаться вдовой, и это побуждает ее распространять свои чары на всех мужчин, способных по своему имущественному положению вступить в брак, с тем чтобы, если это случится, у нее не было недостатка в искателях ее руки» [4, с.405]. Женщина у Канта является постоянной охотницей за мужским полом и мужским вниманием.

В целом, в философии Канта нашла отражение свойственная философским размышлениям Модерна позиция, суть которой заключается в восприятии мужчины как носителя сущности человека вообще, а женщины в качестве выразительницы сущности пола. Можно также отметить, что понимание философа основывается на эссенциалистском подходе, настаивающем на биологическом различии полов и их природном неравенстве. Следует согласиться с точкой зрения И. Грабовской, что «в основе антропологической философии Канта лежит традиционная для западноевропейской классической философии идея человеческой целостности с абсолютно очевидной доминантой маскулинности. Отсюда и ценностно-смысловые установки на рациональное освоение мира и достижения критического разума, позволяющие выискивать недостатки женского ума в так называемом врожденном иррационализме и природной чувствительности» [2, с. 38].

Еще один представитель немецкой классической философии И. Фихте в трактате о праве сформулировал мысли о браке и семье. Философ основывает свои размышления о специфике полового поведения на «двойном стандарте», утверждая, что мужчина и женщина должны руководствоваться разными установлениями в понимании своих социальных свобод и допустимых правил поведения. Философски обосновывая половое неравенство, Фихте писал: «Для разума характерна абсолютная самодеятельность, страдательное состояние противоречит разуму и полностью его устраняет. Поэтому стремление первого пола к удовлетворению своего полового инстинкта соответствует разуму, потому что это происходит посредством деятельности, а соответствующее стремление второго пола совершенно противно разуму, так как целью становится страдательное состояние» [8, с. 300].

В утопии Фихте, названной «Замкнутое торговое государство», ин- 
ститут брака рассматривается как результат реализации полового инстинкта, на основании которого происходит объединение двух лиц разного пола. Поскольку он построен на природном влечении, то принуждение здесь неуместно. Государство, считал Фихте, должно следить за тем, чтобы брак являлся результатом добровольного выбора сторон. После его заключения жена полностью должна подчиняться мужу. Оценивая неверность в браке в соответствии с системой «двойного стандарта», Фихте писал, что неверность в браке мужа и жены должна быть оценена по-разному и соответственно стороны должны нести разные наказания. В общем допуская внебрачные половые связи для мужей, Фихте подчеркивал, что они не наносят существенный урон браку и не ведут к его разрыву, свидетельствуя лишь о дурном поведении мужа, требующем морального, но не правового наказания. Неверность жены в браке ведет к его разрушению, а следовательно, должна обществом более сурово осуждаться. Фихте считал, что полиция должна быть осведомлена о фактах супружеских измен. В отношении проституции позиция философа была жесткой и однозначной. Ее следует запретить, и все, кто ею занимаются, должны быть высланы из страны.

Фихте был толерантен в оценке женских способностей, считая, что в этом отношении женщина стоит не ниже мужчины. Следовательно, нелепо ограничивать человеческие и гражданские права женщин. В то же время, поскольку женщина может быть независимой только до момента вступления в брак, подчеркивал философ, ей не следует занимать горсударственные посты, поскольку в браке она будет занимать подчиненное положение, а это несовместимо с социальным доминированием. А.В.Гулыга отмечал, что «в своем отношении к прекрасному полу Фихте не поднялся выше укоренившихся филистерских представлений. И это (как и третирование природы) отталкивало от него многих» [3, с. 143].

Для немецких романтиков, ярчайшими представителями которых являлись Ф. Шлегель, А.В.Шлегель, Л. Тик, Новалис и Ф. Шлейермахер, характерным в решении проблемы половых различий является опровержение традиционных взглядов на природу женщины, ее способности и вторичное место в обществе. Ориентируясь на идеи Просвещения, романтики настаивали на необходимости обретения самости каждым индивидом, вне зависимости от половой принадлежности. В то же время абстрактно-эссенциалистский подход не мог не оказывать на них влияния, и, опровергая вторичность женщин, они все же проявляли постоянный дуализм в решении проблемы гендерных отличий. 
Ориентируясь на идеал андрогинности в понимании человека, представители философии романтизма утверждали бесконечные возможности человеческой души, и в то же время говорили о характере как реальной жизненной ситуации и позиции, при этом черты женского характера, формирующиеся на основе любви как определяющего экзистенциального состояния, естественно отличали от мужских. С точки зрения романтиков именно развитие особенных женских черт со временем даст возможность освободить мужчин от условных гендерных ролей. Отмечая, что для романтиков характерен отход от старой концепции половых ролей, в соответствии с которой женственность проявлялась прежде всего через связь с природой и домоводство, Н. Чухим отмечала, что полностью опровергнуть традиционные подходы им не удалось, и для их трактовки сущности женского и мужского характерно противопоставление, контраст [7, с.67].

В размышлениях романтиков, как подчеркивают исследователи, уделяется внимание особенностям женской ментальной и эмоциональной конституции. Однако рассмотрение этих особенностей не приводит к утверждению их вторичности и меньшей значимости по сравнению с мужскими качествами. Чаще всего гендерные отличия фиксируются как контрасты, стимулирующие противоположный пол. В частности, романтики утверждают, что любовь в жизни женщины и мужчины имеет различную значимость. «Культ любви» стал важнейшей чертой романтизма, и именно поэтому термин «романтический» стал синонимом «любовного».

Рассматривая женщину прежде всего как объект для поклонения, романтики настаивают на ее равном с мужчиной праве на наслаждение. В 1799 г. Ф.Шлегель создал роман «Люцинда», вызвавший общественный скандал. В своем произведении, опираясь на идею о высоком художественном чутье «в области сладострастия», автор утверждал, что обладать качеством мужественности, кроме прочего, это значит иметь способность не только наслаждаться самому, но и дать наслаждение женщине. Настаивая на том, что обладание высоким художественным чутьем «в области сладострастия» является одновременно и природным даром, и результатом процесса воспитания, Шлегель вступил в конфликт с традиционными представлениями и вызвал поток нелицеприятных оценок своего произведения, которое многие его современники называли «гениальным бесстыдством», «эротической безвкусицей», вызывавшей «скуку и отвращение, удивление и презрение, стыд и тоску».

Шлегель считал, что в отличие от мужчины, который может ди- 
станцироваться от чувства любви, для него часто выступающего лишь как один из частных преходящих интересов, женщина основывает на этом чувстве всю свою жизнь, видя в любви свое основное призвание и смысл существования. Любовь для женщины является тотальной. Философ писал, что именно самодостаточность женской любви способна преобразить жизнь мужчины, придать ей смысл. В то же время, именно с помощью мужской любви женщина обретает самосознание и способность к адаптации в окружающем мире. Оценивая такие подходы, Н. Чухим задает риторический вопрос: «Не является ли такое утверждение возвратом к той же ортодоксальности, которой романтики бросили вызов?» $[7$, с.67].

В соответсвии с идеалами Просвещения, романтики считали, что женщина должна принимать участие в литературных и философских проектах. Высоко оценивая способности женщин, склонных к такого рода занятиям, представители философии романтизма допускали новую модель гендерных отношений, порожденную салонной культурой их времени. Эта культура была пронизана идеями равенства, свободной любви и женского саморазвития.

Умонастроение романтиков наиболее ярко отражается в повести Новалиса «Ученики в Саисе» (1797). Кстати, многие исследователи называют это произведение философским трактатом. Новалис развивает свои философские представления о природе не только как абсолютной реальности, но и игре ума, воображения, сновидения. С его точки зрения, природа таится от человека. Путями проникновения в тайны природы без нарушения первозданной гармонии являются поэзия и искусство. В контексте таких размышлений утверждаются мысли о сущности человеческого счастья и любви, о взаимодействии полов. Повесть «Ученики в Саисе» содержит притчу о юном Гиацинте, который пытается открыть сокровенные тайны бытия и ради этого отправляется на поиски «матери всех вещей». Розенблют, оставленная им ради великих открытий, встречает возлюбленного после долгих скитаний в Саисе. Отбросив покрывало в храме Исиды, Гиацинт с удивлением обнаруживает свою Розенблют. Притча содержит ясную мысль о том, что тайны бытия скрыты в простом чувстве любви. Таким образом, грезы о далеком и несбыточном вполне совместимы для романтиков с возможностью реализации земного, человеческого счастья.

Следует отметить, что снятие в философии романтизма жесткой половой поляризации и понимание несовместимости морального существования с теорией природного предназначения человека, заданного его половой принадлежностью, приводили к утверждению права 
на свободу каждого человеческого существа, а, следовательно, возможности выхода за рамки гендерных ролей, предписываемых каждому полу соответвующими стереотипами, сформированными традиционными обществами.

Вершиной немецкой классики является философия Г.В.Ф.Гегеля. Отражая традиционное для философии своего времени рассмотрение человека как существа, лишенного пола, мыслитель все же считал, что одной из существенных характеристик человеческого является бивалентность человеческого рода - его разделенность на мужской и женский пути бытия. Именно во взаимодействии мужского и женского рождается новая жизнь; их взаимодействие в высших своих проявлениях приводит к переживанию любви. При этом глубинный смысл мужского начала в человеческом бытии выступает как духовность. Под духовностью как неотъемлемой характеристикой мужского понимается способность к рефлексивности, самотрансцендированию, творчеству. Смысл женского заключен в заботливом отношении к бытию, в способности к сочувствию и любви.

Гендерная проблематика присутствует прежде всего в гегелевских работах по философии права, где представлена дихотомия мужского и женского по аналогии с публичным-частным. Здесь женщина выступает как представительница природы, мужчина же является представителем разума. Необходимая связь природы и духа, души и разума устанавливается в браке. Именно через брак как сферу взаимодействия мужского и женского Гегель пытается установить связь природы и Духа. Женское опосредуется через природное, мужское через социальное. «Подавая женщин как представительниц природы, а мужчин как представителей разума,- отмечает Н. Чухим, - Гегель пытается через брак и отношения между женщинами и мужчинами найти связь между сферой природы и духа. Он рассматривает эти сферы как абсолютно разные и неодинаково структурированные. Сфера природы характеризуется цикличным повторением, в котором все элементы расположены рядом и не связаны между собой. Сфера духа это сфера развития, в которой элементы взаимозависимы и взаимодействуют. Более простые явления, принадлежащие сфере природы, становятся понятными через проявления более сложных, которые существуют в сфере духа» $[7$, с. 68]. Исследователи верно отмечают традиционность гегелевских гендерных представлений, в рамках которых женщина символизирует принцип партикулярности, непосредственности, материальности, природности, в то же время мужчина является репрезентантом универсальности, опосредованности, свободы и субъе- 
ктивности. Согласимся с мнением Н. Чухим, которая утверждала, что «гегелевская концепция Духа, несмотря на ее грандиозность, все же не позволила ему в полной мере выйти за пределы «натуралистической» концепции гендера и поместить межполовые отношения в социальный, символический и культурный мир» [7, с.68-69].

Подводя итоги, следует отметить, что в сочинениях представителей немецкой классической философии преимущественно отражено основанное на отношениях доминирования и подчинения, стереотипное представление о сущности пола, мужского и женского, выработанное предыдущими эпохами культурного развития. Оно явилось простым отражением закрепленных в сознании эпохи гендерных стереотипов и никак не могло содействовать построению метафизики, способствующей полной самореализации человеческой личности. В то же время в отдельных положениях философских доктрин, в литературных произведениях наметились новые тенденции, способствовавшие в дальнейшем преодолению традиционного эссенциалистского подхода в трактовке проблем пола.

\section{1 Литература}

[1] Гомілко О. Метафізика тілесності: концепт тіла у філософському дискурсі. - К.: Наукова думка, 2001.

[2] Грабовская И.Н. Пол в антропологической концепции И. Канта и современные гендерные исследования // Вісник ДНУ. Філософія. Соціологія. Політологія. - Вип. 11.

[3] Гулыга А.В. Немецкая классическая философия.-М.: Мысль, 1986.

[4] Кант И.Антропология с прагматической точки зрения // Кант И. Соч. в 6 т. - Т. 6. - М.: Мысль, 1963.

[5] Кант И. Метафизика нравов // Кант И. Соч. в 6 т. - Т. 4. - Ч. 2 М.: Мысль, 1963.

[6] Кант И. Трактаты и письма. - М. 1980.

[7] Чухим Н. Проблематика статі: виникнення та генеза // Основи теорії гендеру: Навчальний посібник. - K.: K.I.C., 2004.

[8] Fichte J.G. Die Grundlage des Naturrechts. - Hamburg, 1979. 